\title{
PENGARUH PENYULUHAN KESEHATAN JAJANAN SEHAT TERHADAP PEMILIHAN JAJANAN SEHAT ORANG TUA PAUD AL-HIKMAH DESA KUNIR LOR LUMAJANG
}

\section{Achlish Abdillah}

(Universitas Jember, Fakultas Keperawatan, Program Studi D3 Keperawatan, Email: achlish@unej.ac.id)

\begin{abstract}
ABSTRAK
Jajanan tidak hygiene sangat beresiko kesehatan dan ada bahan tambahan pangan (BTP) yang dilarang. Jajanan kerap sekali dekat anak terutama anak usia dini atau PAUD. Usia anak ini rentang terhadap penyakit akibat jajanan tidak sehat. Untuk mencegah anak dari jajanan tidak sehat salah satunya pendekatan keluarga dengan pemberian pendidikan kesehatan. Penelitian ini bertujuan mempelajari pengaruh penyuluhan kesehatan tentang pemilihan jajanan sehat terhadap pemilihan jajanan sehat pada anak PAUD Al Hikmah Desa Kunir Lor Kec. Kunir Lumajang Tahun 2017. Metode penelitian menggunakan korelasi jenis rancangan pre-pos tes, Ada 20 sampel dari populasi orang tua Paud Al hikmah yang dipilih secara simple random sampling, pemberian penyuluhan kesehatan sebagai variabel independen sedangkan variabel dependen adalah pemilihan jajanan sehat menggunakan kuesioner, dianalisis menggunakan Paired sample $t-$ test. batuan SPSS versi 17. Hasil penelitian pemberian pendidikan kesehatan sebelum dan sesudah dilakukan penyuluhan ada peningkatan pemahaman jajanan yang sehat, hasil analisis dari 10 soal, ada 4 soal menunjukkan ada hubungan pendidikan kesehatan tentang jajanan sehat terhadap pemilihan jajanan sehat pada orang tua PAUD Al Hikmah Desa Kunir Lor Kec. Kunir Lumajang nilai signifikan kurang 0.05 berturut turut 0.04 (definisi jajanan), 0.02 (jajanan segar ), 0.03 (jajanan bersih) dan 0.00 (jajanan aman ) dengan interval confidence $95 \%$. Proses pemberian penyuluhan kesehatan pemilihan jajanan sehat dapat merubah tingkat pengetahuan serta sikap pemilihan jajanan sehat pada orang tua PAUD, Ketepatan media penyuluhan, menarik saat proses pemberian penyuluhan dapat meningkatkan kemampuan pemahaman pengetahuan dan sikap seseorang. Saran dilakukan penyuluhan pada anak PAUD secara langsung serta model media penyuluhan yang sesuai.
\end{abstract}

Kata Kunci: Penyuluhan, Kesehatan, Pemilihan, Jajanan sehat, Orang Tua , PAUD

\section{ABSTRACT}

Snack foods are at risk for health because they are not hygienic and there are prohibited Food Additives (BTP). Snacks are often very close to children, especially early childhood or PAUD. The age of this child ranges from diseases caused by unhealthy snacks. To prevent children from unhealthy snacks, one of them is the family's approach to providing health education. The aim of the study wes to the effect of health counseling of healthy snacks to the election for parents 
Al Hikmah PAUD children in Kunir Lor Village, subdistrict Kunir Lumajang 2017. The research method used correlation type the pre-test design, the overall population of Paud Al Hikmah's parents with sample size of 20 using a simple random sampling technique, the provision of health counseling is independent variable and the dependent variable is the election of healthy snacks using a questionnaire, analyzed using Paired sample $t$-Test. SPSS rock version 17. The results of the research on the provision of health counseling before and after counseling have increased understanding of healthy snacks, the results of analysis of 10 questions, there are 4 questions showing that there are a relationship between health education about healthy snacks for parents of Al Hikmah PAUD in Kunir Lor Village, subdistrict Kunir Lumajang, significantly reduced the value of 0.05 in a row 0.04 (definition of snacks), 0.02 (fresh snacks), 0.03 (net snacks) and 0.00 (safe snacks) with a 95\% confidence interval. The process of giving health counseling to the election of healthy snacks can change the level of knowledge and attitudes towards choosing healthy snacks for PAUD parents. The accuracy of counseling media is interesting when the counseling process can improve the ability to understand one's knowledge and attitudes. Suggestions for counseling on PAUD children directly and appropriate extension media models.

Keywords: Counseling, Health, Election, Healthy Snacks, Parents, PAUD

\section{PENDAHULUAN}

Agar tubuh tetap sehat dibutuhkan makanan yaitu segala sesuatu yang dikonsumsi melalui mulut untuk kebutuhan tubuh. (DepKes RI, 2001). Jajanan sebagai bagian dari makanan yang mempunyai pengertian yaitu makanan yang banyak ditemukan dipinggir jalan dengan berbagai bentuk, warna, rasa serta ukuran serta menarik perhatian (Irianto, $\mathrm{K}$ (2007). Jajanan yang terkontaminasi dengan mikroba beracun serta mengandung Bahan Tambahan Pangan (BTP) akan beresiko menjadi masalah kesehatan dikarenakan sering tidak higienis (Mudjajanto, 2006)

Sering kali jajanan tersebut sangat dekat dengan anak terutama anak usia dini atau PAUD. Usia anak ini rentang terhadap penyakit terutama diare yang diakibatkan dari jajanan yang tidak sehat. Hasil temuan banyak peneliti sudah membuktikan bahwa jajanan makanan 15 jajanan $(71,14 \%)$ mengandung formalin, 4 jajanan $(23,5 \%)$ mengandung boraks, serta 5 jajanan $(18,5 \%)$ ada kandungan rhodamin B (Kristianto dkk , 2013) Kecenderungan anak belum punya pengetahuan yang mendalam apakah makanan itu sehat atau tidak tetapi yang diinginkan disesuaikan dengan selera. Menurut Ananto P, 2016, kebiasaan jajan anak dipengaruhi oleh kemasan yang menarik, rasanya yang enak dan faktor fisik

Berdasarkan Data BP POM RI didapat 35 kejadian keracunan yang terjadi di berbagai wilayah Indonesia yang diperoleh dari 138 media massa 
online kurun waktu antara April hingga Juni 2016.

Kejadian luar biasa (KLB) keracunan jajanan yang tidak sehat dapat dicegah salah satunya dengan pendekatan melalui keluarga diantaranya pemberian pendidikan dan kesehatan terutama pemilihan jajanan yang sehat bagi anakanaknya. Pemahaman tingkat pengetahuan dan sikap dapat ditingkatkan dengan kegiatan pendidikan dan penyuluhan kesehatan (Notoatmodjo, 2003)

Berdasarkan alasan diatas maka peneliti ingin meghubungkan bagaimana pendidikan kesehatan tentang jajanan yang sehat dengan pemilihan jajanan sehat di keluarga dengan rumusan masalah yaitu Adakah pengaruh penyuluhan kesehatan pemilihan jajanan sehat terhadap pemilihan jajanan sehat pada orang tua PAUD Al Hikmah Desa Kunir Lor Lumajang Tahun 2017 ?.

Penelitian ini bertujuan mempelajari pengaruh penyuluhan kesehatan tentang pemilihan jajanan sehat terhadap implementasi pemilihan jajanan sehat pada orang tua PAUD Al Hikmah Desa Kunir Lor Lumajang Tahun 2017

\section{METODE PENELITIAN}

Desain korelasi jenis rancangan pre-pos tes digunakan untuk menjawab tujuan penelitian yaitu sebelum diukur diberikan penyuluhan tentang pendidkan kesehatan jajanan sehat dan pos tes diukur kembali tentang pemilihan jajanan sehat melalui pengetahuan dan sikap pada orang tua Paud Al hikmah Desa Kunir Lor Kec. Kunir Lumajang. Penelitian dilakukan dari tanggal 14 September 2017 sd 14
Oktober 2017. Populasi sasaran dalam penelitian ini adalah keseluruhan orang tua Paud Al hikmah Desa Kunir Lor Kec. Kunir Lumajang yang ada di lokasi penelitian. Sedangkan jumlah populasi sumber berjumlah 35 orang tua siawa Paud Al hikmah Desa Kunir Lor Kec. Kunir Lumajang. Peneliti mengambil 20 responden yang dipilih secara simple random sampling dengan batasan kriteria sebagai berikut: orang tua Paud $\mathrm{Al}$ Hikmah dengan anak masih berstatus sekolah PAUD, saat penelitian responden berada di lokasi dan bersedia dengan mengisi lembar persetujuan.

Variabel penelitian terdiri variabel independen yaitu pemberian penyuluhan kesehatan sedangkan dependen adalah pemilihan jajanan sehat. Untuk variabel pemberian penyuluhan kesehatan peneliti dengan memberikan penyuluhan tentang informasi dan pengetahuan untuk meningkatan pemahaman tentang jajanan yang sehat bagi anak terdiri pengertian jajanan sehat, penjual makanan, syarat makanan jajanan segar, bersih dan aman serta hasil pengetahuan diukur menggunakan instrument kuesioner dalam skala data katagorikal. Sedangkan variabel pemilihan jajanan sehat menggunakan instrument kuesioner untuk mengukur sikap pemahaman pemilihan jajanan sehat ada 10 butir soal yaitu soal nomor 1 tentang pengertian makanan, soal nomor tentang pengertian makanan jajanan, soal nomor 3 tentang syarat penjual makanan jajanan, soal nomor 4 tentang cuci tangan penjual jajanan sebelum menyajikan, soal nomor 5 tentang penjual jajanan menggunakan alas makanan 
sebelum menyajikan, soal nomor 6 tentang larangan penjual jajanan menggaruk anggota badan, soal nomor 7 tentang syarat makanan jajanan sehat, soal nomor 8 tentang syarat makanan jajanan yang segar, soal nomor 9 tentang syarat makanan jajajanan yang sehat, serta soal nomor 10 tentang syarat makanan jajanan yang aman.

Agar didapat valid dan ajeg pada alat ukur, peneliti melakukan uji validitas dan reliabilitas secara Alpha Cronbach, Data karakteristik sampel dideskripsikan dalam mean, $\mathrm{SD}$, minimum, maksimum. Untuk mendeskripsikan karakteristik sampel dalam bentuk tabel frekuensi dan persentase. Peneliti menganalisis dengan Paired sample $t$-test untuk menjawab hipotesa hubungan antara pemberian pendidikan kesehatan dengan pemilihan jajajanan sehat.

\section{HASIL PENELITIAN}

Pengaruh penyuluhan kesehatan tentang pemilihan jajanan sehat terhadap implementasi pemilihan jajanan sehat pada anak PAUD Al Hikmah Desa Kunir Lor Lumajang Tahun 2017 hasilnya digambarkan sebagai berikut. Pada tabel 1. dibawah ini menunjukkan bahwa separuh usia responden antara 26-30 tahun.

Tabel 1. Distribusi usia orang tua PAUD karakteristik Al Hikmah Desa Kunir Lor Lumajang Th 2017

\begin{tabular}{cccc}
\hline No & Usia orang tua & Frekuensi & Persentase \\
\hline 1 & Antara 20 - 25 tahun & 3 & $15 \%$ \\
\hline 2 & Lebih dari 26 - 30 tahun & 10 & $50 \%$ \\
\hline 3 & diatas 30 tahun & 7 & $35 \%$ \\
\hline & Total & 20 & $100 \%$ \\
\hline
\end{tabular}

Pada tabel 2 dibawah ini menunjukkan bahwa seluruh responden berjenis kelamin wanita atau $\quad 100$
$\%$

Tabel 2. Distribusi karakteristik gender responden orang tua PAUD Al Hikmah Desa Kunir Lor Lumajang Th 2017

\begin{tabular}{cccc}
\hline No & Gender & Frekuensi & Persentase \\
\hline 1 & wanita & 20 & $100 \%$ \\
\hline 2 & pria & 0 & $0 \%$ \\
\hline & Total & 20 & $100 \%$ \\
\hline
\end{tabular}

\section{PEMBAHASAN}

Dari hasil pemberian pendidikan kesehatan sebelum dan sesudah dilakukan penyuluhan ada peningkatan pemahaman tentang apa yang dimaksud dengan jajanan yang sehat berdasarkan hasil kuesione dengan 10 soal sebelum dilakukan 
Sedangkan untuk melihat

pendidikan kesehatan dan setelah dilakukan pendidikan kesehatan dengan pertanyaan bagaimana definisi makanan, jajan sehat, syarat penjual makanan jajanan, tata cara menyajikan jajan yang sehat, serta syarat jajan yang bersih, aman sehat . Hasil tersebut sesuai penelitian Fahriani Syahrul, 2005 (FKM Unair) menemukan bahwa untuk mencegah kasus-kasus keracunan makanan diantaranya 1. perlu adanya peningkatan pengetahuan tentang keracunan makanan 2. perlu adanya penyuluhan dan pembinaan kepada masyarakat. Dengan kata lain bahwa untuk memberikan pengetahuan dan pemahaman tentang jajanan sehat dapat dilakukan dengan memberikan penyuluhan kepada masyarakat dan pada penelitian ini melalui orang tua Paud Al Hikmah Kunir Kab. Lumajang. pengaruh penyuluhan kesehatan tentang pemilihan jajanan sehat terhadap implementasi pemilihan jajanan sehat pada orang tua PAUD Al Hikmah Desa Kunir Lor Lumajang Tahun 2017, hasil analisis Paired sample $t$-test adalah bahwa dari 10 soal, ada 4 soal menunjukkan ada hubungan penyuluhan kesehatan tentang jajanan sehat dengan pemilihan jajanan sehat pada orang tua PAUD Al Hikmah Desa Kunir Lor Tahun 2017 yang ditunjukkan dengan nilai signifikan sebesar 0.04 untuk soal 1 (definisi jajanan), soal 8 (syarat jajanan segar) signifikan nilai sebesar 0.02 , soal 9 (syarat jajanan bersih) signifikan nilai sebesar 0.03 serta soal 10 (syarat jajanan aman) dengan nilai signifikan sebesar 0.00 dengan interval confidence $95 \%$ yang tertera sesuai tabel 3 berikut.

Tabel 3. Pengaruh penyuluhan kesehatan pemilihan jajanan sehat terhadap implementasi pemilihan jajanan sehat pada orang tua PAUD Al Hikmah Desa Kunir Lor Lumajang Tahun 2017

Paired Samples Test

\begin{tabular}{|c|c|c|c|c|c|c|c|c|}
\hline & \multicolumn{5}{|c|}{ Paired Differences } & \multirow[t]{3}{*}{$\mathrm{t}$} & \multirow[t]{3}{*}{$\mathrm{df}$} & \multirow{3}{*}{$\begin{array}{c}\text { Sig. } \\
(2- \\
\text { tailed })\end{array}$} \\
\hline & \multirow[t]{2}{*}{ Mean } & \multirow[t]{2}{*}{$\begin{array}{c}\text { Std. } \\
\text { Deviation }\end{array}$} & \multirow[t]{2}{*}{$\begin{array}{l}\text { Std. } \\
\text { Error } \\
\text { Mean }\end{array}$} & \multicolumn{2}{|c|}{$\begin{array}{l}95 \% \\
\text { Confidence } \\
\text { Interval of the } \\
\text { Difference }\end{array}$} & & & \\
\hline & & & & Lower & Upper & & & \\
\hline Pair $1 \mathrm{~J} 1$ - K1 &,- 250 &, 851 & 190 &,- 648 & 148 & $-1,314$ & 19 & ,204 \\
\hline Pair $2 \mathrm{~J} 2-\mathrm{K} 2$ &,- 550 & ,759 & , 170 &,- 905 &,- 195 & $-3,240$ & 19 & ,004 \\
\hline Pair 3 J3 - K3 &,- 250 &, 716 &, 160 &,- 585 & ,085 & $-1,561$ & 19 &, 135 \\
\hline
\end{tabular}




\begin{tabular}{|ll|r|r|r|r|r|r|r|r|} 
Pair 4 & J4 - K4 &,- 200 &, 523 &, 117 &,- 445 &, 045 & $-1,710$ & 19 &, 104 \\
Pair 5 & J5 - K5 &,- 450 &, 686 &, 153 &,- 771 &,- 129 & $-2,932$ & 19 &, 009 \\
Pair 6 & J6 - K6 &,- 150 &, 489 &, 109 &,- 379 &, 079 & $-1,371$ & 19 &, 186 \\
Pair 7 & J7 - K7 &,- 350 &, 988 &, 221 &,- 812 &, 112 & $-1,584$ & 19 &, 130 \\
Pair 8 & J8 - K8 &,- 600 &, 754 &, 169 &,- 953 &,- 247 & $-3,559$ & 19 &, 002 \\
Pair 9 J9 - K9 &,- 750 &, 967 &, 216 & $-1,202$ &,- 298 & $-3,470$ & 19 &, 003 \\
Pair & J10 - & - & 1,465 &, 328 & $-2,286$ &,- 914 & $-4,883$ & 19 &, 000 \\
10 & K10 & 1,600 & & & & & & & \\
\hline
\end{tabular}

\section{PEMBAHASAN}

Dari hasil pendidikan kesehatan sebelum dan sesudah dilakukan penyuluhan ada peningkatan pemahaman tentang apa yang dimaksud dengan jajanan yang sehat setelah dilakukan proses penyuluhan.

Hasil tersebut sesuai penelitian menurut Fahriani Syahrul, 2005 (FKM Unair) menemukan bahwa untuk mencegah kasus-kasus keracunan makanan diantaranya perlu adanya peningkatan pengetahuan tentang keracunan makanan dan perlu adanya penyuluhan dan pembinaan kepada masyarakat.

Dengan kata lain bahwa untuk memberikan pengetahuan dan pemahaman tentang jajanan sehat dapat dilakukan dengan memberikan penyuluhan kepada masyarakat dan pada penelitian ini melalui orang tua Paud Al Hikmah Kunir Kab. Lumajang.

Hasil tersebut mendukung penelitian Isti Mulyawati.dkk, 2017 bahwa pengetahuan dan sikap anak tentang keamanan jajanan dipengaruhi oleh pendidikan kesehatan serta hasil penelitian ini juga mendukung penelitian Fitriani, 2015 anak memiliki sikap positif dalam memilih makanan jajan yang dilaksanakan di SDN II Tagog Apu Padalarang ditunjukkan 89,8 \%. Penyuluhan kepada anak menyebabkan peningkatan pengetahuan khususnya pada pemilihan jajanan yang sehat. Selain itu pengetahuan yang baik tentang kesehatan akan membentuk sikap yang positif oleh Booth et al, 2013. Menurut Peneliti berdasarkan hasilhasil penelitian diatas dapat dikatakan sikap seseorang akan dipengaruhi oleh pengetahuannya.

Pada penelitian ini fokus bagaimana pendidikan kesehatan tentang jajanan sehat pada orang tua Paud Al-hikmah terhadap pemilihan jajanan yang sehat. Dari hasil pendidikan kesehatan sebelum dan sesudah dilakukan penyuluhan ternyata didapatkan ada peningkatan pemahaman tentang apa yang dimaksud dengan jajanan yang sehat.

Tentang hasil penelitian pengaruh penyuluhan kesehatan pemilihan jajanan sehat terhadap implementasi pemilihan jajanan sehat pada anak PAUD Al Hikmah Desa Kunir Lor Lumajang Tahun 2017 yang dianalisis menggunakan 
Paired sample $t$-test didapatkan bahwa ada 4 soal dari 10 soal menunjukkan ada hubungan yang signifikan pendidikan kesehatan tentang jajanan sehat dengan pemilihan jajanan sehat pada orang tua PAUD Al Hikmah Desa Kunir Lor yaitu soal 2 (definisi jajanan) signifikan sebesar 0.04 , soal 8 (syarat jajanan segar) signifikan sebesar 0.02 , soal 9 (syarat jajanan bersih) signifikan sebesar 0.03 dan soal 10 (syarat jajanan aman) signifikan sebesar 0.00 dengan interval confidence $95 \%$

Untuk pertanyaan definisi tentang jajanan ada hubungan yang signifikan dengan nilai sebesar 0.04 setelah dilakukan pendidikan kesehatan hal ini dikarenakan konsep makanan jajanan hampir semua sudah mengerti karena merupakan prinsip yang harus diketahui oleh semua ortang tua.

Hasil tersebut menjelaskan bahwa pengetahuan dan sikap anak tentang keamanan jajanan dipengaruhi oleh pendidikan kesehatan sesuai penelitian Isti Mulyawati.dkk, 2017 yaitu sebesar $0,7 \%$. Hal sama juga terjadi pada pemberian pendidikan kepada orang tua Paud Al Hikmah Desa Kunir Kec. Kunir Kab. Lumajang.

Untuk pertanyaan syarat jajanan yang segar dari hasil penelitian bersignifikan sebesar 0.02 setelah dilakukan pendidikan kesehatan hal ini menunjukkan syarat jajanan yang segar hampir semua sudah dimengerti, ini adalah prinsip yang harus diketahui oleh semua orang tua lebih-lebih bila akan memberikan makanan kepada buah hatinya.

Sedangkan untuk pertanyaan syarat jajanan yang bersih dari hasil penelitian bersignifikan sebesar 0.03 setelah dilakukan penyuluhan kesehatan hal ini dikarenakan syarat jajanan yang bersih hampir semua sudah mengerti. Hal tersebut merupakan prinsip yang harus diketahui oleh semua orang tua lebih-lebih bila akan memberikan makanan kepada anaknya.

Serta untuk pertanyaan syarat jajanan yang aman dari hasil penelitian bersignifikan sebesar 0.00 setelah dilakukan penyuluhan kesehatan hal ini dikarenakan syarat jajanan yang aman hampir semua sudah mengerti . Keamanan jajanan adalah prinsip yang harus diketahui oleh semua orang tua lebih-lebih bila akan memberikan jajanan kepada buah hatinya, selain itu keamanan makanan mutlak tidak boleh diabaikan agar tetap sehat saat mengkonsumsi jajanan.

$$
\text { Penjelasan diatas sejalan }
$$
dengan hasil penelitian Fitriani, 2015 anak memiliki sikap positif dalam memilih makanan jajan yang dilaksanakan di SDN II Tagog Apu Padalarang ditunjukkan 89,8 \%. Penyuluhan kepada anak menyebabkan peningkatan pengetahuan khususnya pada pemilihan jajanan yang sehat. Hal ini disebabkan pengetahuan anak tentang pemilihan makanan jajan sudah baik. Selain itu pengetahuan yang baik tentang kesehatan akan membentuk sikap yang positif oleh Booth et al, 2013. Akhirnya menurut Peneliti berdasarkan hasil-hasil penelitian diatas dapat dikatakan sikap seseorang akan dipengaruhi oleh pengetahuannya demikian juga saat orang tua Paud di Al-Hikmah Desa Kunir Kec. Kunir Kab. Lumajang dimana setelah mendapatkan pengetahuan melalui proses penyuluhan melalui 
penggunaan metode dan pemilihan media yang cocok dan tepat. Hal ini sesuai hasil penelitian Menurut Notoatmodjo (2003) bahwa salah satu strategi untuk meningkatkan pengetahuan dan sikap adalah dengan adanya penyuluhan atau pendidikan kesehatan.

Penggunaan media film, VCD, dan televisi memiliki intensitas lebih tinggi daripada hanya kata-kata dan tulisan. Media sederhana seperti leaflet, poster, lembar balik, buku bergambar, dan lain-lain meskipun digunakan dengan intensitas yang rendah masih mempunyai banyak keuntungan diantaranya: mudah dimengerti bahasanya; media yang dibuat bisa menyesuaikan sasaraan atau audien; kebiasaan, kehidupan, kepercayaan setempat dapat dicerminkan oleh ilustrasi media yang sederhana; serta dapat belajar mandiri yang efektif tanpa banyak mencatat; selain itu media sederhana tersebut dapat memberikan informasi tanpa harus banyak tulisan; keuntungan terakhir adalah memiliki kemudahan dibuat, digandakan, direvisi. ( Notoatmodjo, 2010)

Dari butir soal makanan yang sehat, syarat jajanan segar, sehat dan aman merupakan substansi dari jajanan yang sehat yang harus dimilki dan dipahami oleh para orang tua dalam memberikan jajanan yang sehat kepada anaknya. Dengan demikian dapat disimpulkan bahwa ada hubungan pemberian penyuluhan kesehatan tentang jajanan dengan pemilihan jajanan yang sehat pada orang tua Paud Al-Hikmah Desa Kunir Kec. Kunir Kab. Lumajang.

\section{SIMPULAN}

Pemberian penyuluhan kesehatan sebelum diberikan dengan setelah diberikan penyuluhan kesehatan ada korelasi terhadap tingkat pengetahuan orang tua PAUD Al hikmah Desa Kunir Lor Kec. Kunir Kab. Lumajang.

Terdapat pengaruh yang secara statistik signifikan berdasarkan analisis Paired sample $t$-test pemberian penyuluhan kesehatan dengan implementasi pemilihan jajanan sehat orang tua PAUD Al hikmah Desa Kunir Lor Kec. Kunir Kab. Lumajang yang ditunjukkan berturut-turut definisi jajanan signifikan sebesar 0.04 , syarat jajanan segar signifikan sebesar 0.02, syarat jajanan bersih signifikan sebesar 0.03 dan syarat jajanan aman signifikan sebesar 0.00 dengan interval confidence $95 \%$

Bahwa proses pemberian penyuluhan kesehatan pemilihan jajanan sehat dapat merubah tingkat pengetahuan serta sikap dalam implementasi pemilihan jajanan yang sehat pada orang tua PAUD Al Hikmah Desa Kunir Lor Kec. Kunir Kab. Lumajang. Selain itu penggunaan media yang sesuai dan tepat serta menarik saat proses pemberian penyuluhan kesehatan atau penyuluhan dapat meningkatkan kemampuan pemahaman pengetahuan dan sikap seseorang.

\section{SARAN}

Bagi penelitian berikutnya agar menggunakan populasi dengan besar sampel yang tidak terbatas. Selain itu perlu dilakukan penelitian mengenai hubungan pemberian penyuluhan kesehatan tentang jajanan sehat pada anak PAUD 
secara langsung bukan kepada orang tua serta perlu dilakukan penelitian mengenai pemilihan model media penyuluhan yang sesuai pada anak PAUD.

\section{DAFTAR PUSTAKA}

Anonim. 2002. Memilih Makanan dan Jajanan yang Sehat. Balitbang Depdiknas dan Lembaga Penelitian IPB. Bogor.

Booth Rachelle, Magaly H, Erica L, Tevni G, \& Peter P. 2013. Food Safety Attitudes in College Students: A Structural Equation Modeling Analysis of a Conceptual Model. Nutrients， 5(2), 328-339 Brakkmann Nils. 2010.

Depkes RI. 2001. Pedoman

Penyuluhan Gizi pada Anak

Sekolah bagi Petugas

Puskesmas. Jakarta.

Depkes RI. 2004. Hygiene Sanitasi

Makanan dan Minuman

(HSMM). Buku Pedoman

Akademi Penilik Kesehatan.

Jakarta.

Depkes RI. 1994. Pedoman

Pengelolaan dan

Penyehatan Makanan

Warung Sekolah. Jakarta.

Fitriani Neng L, Septian A. 2015.

Hubungan Antara

Pengetahuan dengan Sikap

Anak Usia Sekolah Akhir

(10-12 Tahun) Tentang
Makanan Jajanan di SD

Negeri II Tagog Apu

Padalarang Kabupaten

Bandung Barat Tahun

2015. Artikel Penelitian

Harper, Laura J. 1989. Pangan, Gizi dan Pertanian. Penerbit Universitas Indonesia. Jakarta.

Irianto, DP. 2007. Panduan Gizi Lengkap : Keluarga dan Olahragawan. CV. Andi offset. Yogyakarta.

Irianto, K. 2007. Gizi dan Pola Hidup Sehat. CV. Yrama Widya. Bandung

Khomsan, A. 2003. Pangan dan Gizi untuk Kesehatan. PT. Raja Grafindo Persada. Jakarta.

Maulana, Heri, d, j. 2009. Promosi Kesehatan. Jakarta: Penerbit Buku Kedokteran EGC

Mudjajanto,E S. 2006. Keamanan Makanan Jajanan Tradisional.Penerbit Buku Kompas. Jakarta.

Murti,B.2010. Desain dan Ukuran Sampel Untuk Penelitian Kuantitatif dan Kualitatif. Edisi ke-2. Yogyakarta.Gajah Mada University Press

Murti,B.2006. Desain dan ukuran sampel untuk penelitian kuantitatif dan kualitatif di 
bidang kesehatan. Riduwan.2009.Metode dan Teknik Yogyakarta: Gadjah Mada Menyusun Tesis.Cetakan University Press.

Notoatmodjo, Soekijo. 2010. Ilmu keenam. Bandung.Alfabeta Perilaku Kesehatan. Jakarta: Rineka Cipta.

Notoatmodjo, Soekijo. 2003. Prinsipprinsip Dasar Ilmu Kesehatan. Jakarta: Rineka Cipta.

Sitorus, L. 2007. Pengetahuan, Sikap dan Tindakan Siswa Sekolah Dasar Tentang Makanan dan Minuman yang Mengandung Bahan Tambahan Makanan pada Sekolah Dasar di Kecamatan Medan Denai. Skripsi FKM USU. Medan

Nur,et al.1999. Teori Belajar. Surabaya: University Press Universitas Negeri Surabaya. 